\title{
ETHICS: The Past, Present and Future of Socio-Technical Systems Design
}

\author{
Shona Leitch and Matthew J. Warren \\ School of Information Systems,Faculty of Business and Law, \\ Deakin University, Burwood, Victoria, Australia, 3125 \\ matthew. warren@deakin.edu.au
}

\begin{abstract}
Since computers were first introduced in the late 1960's there has been continued debate on the impact of technology, organisations and staff within those organisations. Enid Mumford was one of the key researchers who looked at the Socio-Technical implications through the decades, and as part of her research she developed the ETHICS method to help improve the integration of technology in organisations and society.
\end{abstract}

Keywords: Enid Mumford, ETHICS, participation, and systems design.

\section{Introduction}

Across the globe, there are now many different types of Information Systems in place, from databases, expert systems, cloud computing application, transaction processing systems, Internet based systems, decision support systems, etc. The use of these systems is very different from global Internet based systems, organisational systems to personal systems where the number of users can vary from three hundred million users to a single user.

The computer revolution was predicted in the late 60's and during the next thirty years we saw the introduction of corporate computer systems, personal computer systems, home micro computers and the development of the Internet. Enid Mumford understood the impact that technology and systems would have upon us all and her research over the decades focused upon the issue of this impact; on organisations as well as on the individual.

This paper will explore the early social-technical research, the development of the ETHICS model and how this has changed over the years and includes a discussion of how Enid Mumford's research could influence future research areas and focus.

\section{History of Socio Technical Design}

According to Mumford and Beekman (1994), the Socio-Technical system design was the product of a group of social scientists who came together at the end of the Second World War and formed the Tavistock Institute of Human Relations in London. The Tavistock Institute was established in 1946 by this group, many of whom had collaborated in wartime projects and most of whom had been members of the Tavistock Clinic before the war. The Tavistock Clinic was a therapeutic establishment 
concerned with mental health and individual development and this was also the initial focus of the members of the Institute, although they were applying their ideas to workers in industry. In 1949, the Tavistock Institute made its first major contribution to the theory of Socio-Technical design with a number of field projects in the British coal industry.

Mumford and Beekman (1994) identified that the major outcome of the early Socio-Technical research was:

"If a technical system is created at the expense of a social system, the results obtained will be sub-optimal."

\section{Development of ETHICS}

Based upon Mumford's Socio-Technical experiences she developed the the participational method known as ETHICS (Effective Technical and $\underline{\text { Human }}$ Implementation of

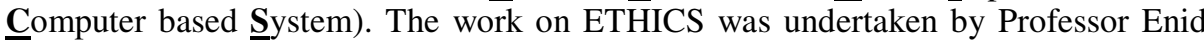
Mumford during her time at Manchester Business School, UK (Mumford, 1983a).

ETHICS is a participational (also referred to as a Socio-Technical approach) approach that focuses upon people and procedures. This Socio-Technical approach is defined by Mumford as "one which recognises the interaction of technology and people and produces work systems which are both technically efficient and have social characteristics which lead to high job satisfaction" (Mumford, 1983b).

The ETHICS approach was based on the observation of failure of many systems which followed more traditional route of considering technical and economic factors (Davis et al, 1992). One of the key motivating questions was whether or not analysts and designers held a view of users that was different from that held by the users of information systems. From these observations, Mumford concluded that the development of information systems is not a purely technical issue, but an organisational issue which is fundamentally concerned with the process of change (Mumford and Weir, 1979; Mumford, 1995).

The use of participation allows users to have some level of contribution in the system development life cycle, this participation often take the form of single representatives. The user participant is often called upon after the major decisions have been taken; this limits the user participation of involvement within the system development (Nurminen, 1988).

The original ETHICS methods were developed in the UK in the late 1960's to deal with the impending information revolution (Mumford and Ward, 1968) of the 1970's. The early conceptual models of ETHICS were concerned with: ensuring users were satisfied with their jobs and trying to determine the impact that computers could have upon their job; and the perception that computers were perceived as agents of change within organisations.

These principles were used as the foundation of the formalised ETHICS method. Around this time Mumford (1969) examined the impact of implementing computers within organisations, and determined that the successful introduction of technical changes required: the use of interdisciplinary planning teams, particularly when goals and objectives are being defined; awareness of the fact that technical changes have secondary as well as primary consequences; and planning does not take place in a static situation. 


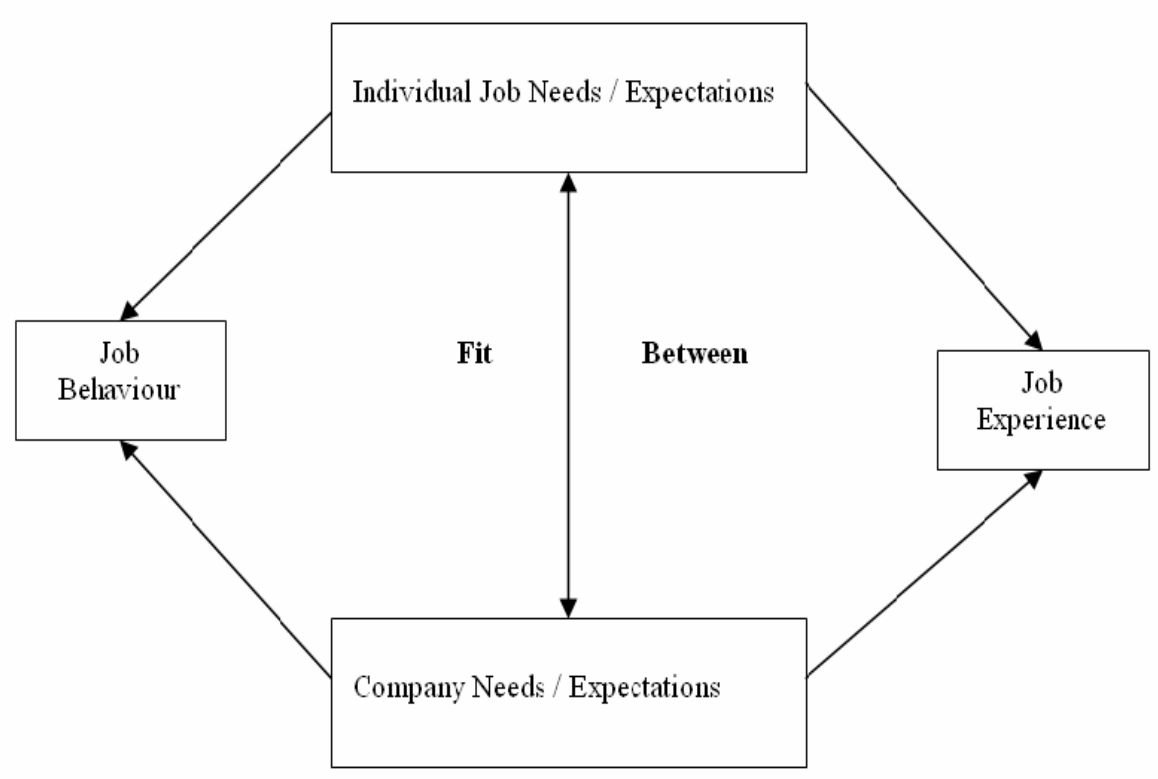

Fig. 1. Conceptual model describing the benefits of technology

The original systems that were being evaluated using this approach were office computer systems and the impact that their introduction would have on office clerks (Mumford and Banks, 1967). Much of this earlier research was based upon trying to determine the impact of these newer technologies, such as micro-computers upon organisations. By the late 1970's the use of technology within organisations was more common and were becoming formalised and we started to see models being developed (Legge and Mumford, 1978) to describe complex issues. This research went beyond the simple analysis of impact on an organisation and began to considering the effects that the use of computers would have on the individuals within the organisation, including changes to job roles, individuals' perceptions, behaviour and needs, expectations and job satisfaction. An example of one of Mumford's earlier models relating to the benefits of technology is shown by Figure 1 (above).

A key area in her earlier research is the concept of job satisfaction; Mumford and Weir (1979) define job satisfaction as:

the attainment of a good "fit" between what the employee is seeking from his work - his job needs, expectations and aspirations - and what he is required to do in his job - the organisational job requirements which mould his experience.

This definition draws upon earlier work looking at the job satisfaction of computer specialists (Mumford, 1972). A continuation of the research by Mumford saw continued development in the key area of participation and how different forms of participation 
could be used within the ETHICS method. Mumford (Mumford and Henshall, 1979) defined the following levels of participation:

1. Consultative - This is when an existing body, e.g. steering committee, is used to implement the change process. This committee would then consult users on the effect that change would have upon them;

2. Representative - This is when a cross selection of users affected by change, are brought together into a design group. This ensures that representatives effected by change have the same powers in the committee as those bringing about change; and;

3. Consensus - This is when all the staff impacted by the change are involved in the design process. Representatives of the staff are elected to form the design committee.

Another key area is the unique view of the Socio-Technical approach. Mumford (1983a) redefines the Socio-Technical approach as:

"one which recognises the interaction of technology and people and produces work systems which are both technically efficient and have social characteristics which lead to high job satisfaction."

The research undertaken by Mumford is encapsulated in the ETHICS methodology (Mumford and Weir, 1979) to implement system design. The earlier ETHICS methodology consisted of seven stages, which are (Mumford and Weir, 1979):

Step1 - Diagnosis: Determine the information required for the diagnosis of human needs, collected through the use of questionnaires. The results of the survey are analysed to determine user needs, the new system should be designed to meet user requirements, as far as possible;

Step2 - Socio-Technical system design: Define the human objectives, which the new system should achieve, based on the social diagnosis of step 1;

Step 3 - Setting out alternative solutions: Define the possible social and technical solutions in order to achieve the desired requirements of step 1 and step 3;

Step 4 - Setting out possible Socio-Technical solutions: Combine the separate social and technical solution into a combined list of solutions;

Step 5 - Ranking Socio-Technical solutions: List the Social-Technical solutions which achieve the objectives set in step 2 and cater for the human needs as defined within step 1 ;

Step 6 - Preparing a detailed work design: Develop system specifications and work plans for the top choices from step 5;

Step 7 - Accept the best possible Social Technical solutions: Evaluate the plans from step 6 and implement the best possible Socio-Technical solution.

Committees of individual users, managers and IT staff would be the ones who would conduct the different stages of the ETHICS methodology. The original ETHICS methodology was extended to take into consideration such issues as availability and reliability of the systems once they have been introduced. The introduction of new technology into an organisation can also be thought of as a human issue, relating to (Mumford, 1995): 
User requirements: New technology directly affects users. There is little evidence that managers have recognised the need of using IT to change the way they do business. User requirements should be incorporated fully into the system design from the start so that the system that is designed actually complies with user requirements; and

User job satisfaction: The way in which a computer can have a direct effect upon the user and the way they use the system. If the user is unsatisfied with the system they will become less motivated and users will take longer to carry out tasks, or might not even use the system at all.

It was during the 1980's that micro computers began to have an obvious impact upon organisations. Mumford undertook a number of projects in the 1980's using ETHICS to redesign administrational support systems, in particular secretary systems (Mumford, 1983c). Also during this time ETHICS was used to develop unusual systems such as an expert system for Digitial Equipment Corporation (DEC), the XSEL system was developed for their sales office to help configure DEC hardware system for customers (Mumford and MacDonald, 1989). The ETHICS principles were also used to determine the value system of large organisations (Mumford, 1981).

During the eighties, the ETHICS methodology was expanded to fifteen levels (Mumford, 1986), the stages were:

Stage 1 - Why Change? Determine whether there is need for change;

Stage 2 - System Boundaries: Identify the boundaries of the system that has to be developed;

Stage 3 - Description of existing systems: Determine how the existing system works looking at issues such as the sequence of events within that system;

Stage 4,5,6 - Definition of key objectives and tasks: From the analysis of the system determine what the key tasks and objectives are and related information;

Stage 7 - Diagnosis of efficiency needs: Determine possible weak links in the existing system;

Stage 8 - Diagnosis of job satisfaction needs: Determine users' perception of the current system in regards to job satisfaction. This would be carried out via the use of questionnaires. The results of the questionnaire would be drawn into the actual system design;

Stage 9 - Future Analysis: An analysis of the future requirements of the system is undertaken, this is to ensure that the system design covers possible areas of potential change;

Stage 10 - Specifying and weighting job satisfaction: Rank the key objectives based upon the analysis of stages 7,8 and 9;

Stage 11 - Organisational design of the new system: Develop a design of the system that focuses upon the issues identified relating to efficiency, job satisfaction, etc (this runs in parallel with Stage 12);

Stage 12 - Technical Options: Determine the technical aspect of the system including issues such as hardware, software, human-computer interface, etc;

Stage 13 - Preparation of a detailed work design: Prepare the system plan in more detail e.g. defining data flows, responsibilities, etc;

Stage 14 - Implementation: Oversee the implementation of the work design plan;

Stage 15 - Evaluation: Evaluate the new system to ensure that it complies with the required objectives. 
A number of criticisms of the ETHICS method have been expressed (Avison and Fitzgerald, 2006):

- $\quad$ unskilled users cannot design;

- $\quad$ management will not accept it; and

- $\quad$ it removes the right to manage from managers

- $\quad$ slow and costly in staff time and effort

To overcome some of these concerns over the applicability of ETHICS, a newer version of ETHICS was developed called QUICKethics (QUality Information from Considered Knowledge) (Mumford, 1993). It was developed to create and maintain management interest (Avison and Fitzgerald, 1995) and it is broken down into five main stages:

- Describe the work mission, key tasks, critical success factors and most serious problems.

- Describe the objectives, critical success factors, major problem, day-today activities, and potentials for future developments associated with each of the key tasks.

- Describe the information needs associated with these tasks in order to achieve the objectives, attain critical success factors and avoid major problems, as well as monitoring performance and understanding future developments.

- $\quad$ Prioritise these information needs according to which are essential and which merely desirable, and which are quantitative and which are qualitative.

- Work with others to establish an information model so that information flows through the organisation to those who require it.

(Mumford, 1983b)

Whilst the standard ETHICS Methodology was a top down, user driven approach, Mumford rejected this approach in her QUICKethics approach and concentrated the methodology as starting from the centre and forming small working groups as a core part of the process (Mumford, 1983b). By working in this way many of the benefits of participative development could be achieved but in a much shorter timeframe than under the ETHICS methodology.

Mumford also proposed using QUICKethics as part of the PROGRESS method to help in Business Process Re-Engineering. The aim of this approach was to rethink and restructure business processes so to make them more efficient, more effective in achieving business goals and more able to provide a high quality work environment that motivates employees (Mumford and Beekman, 1994).

\section{Analysis of ETHICS}

A common reaction to ETHICS is for researchers to say that it is impractical (Avison and Fitzgerald, 2006) due to the structured nature of the ETHICS and QUICKethics approaches. Another common criticism of the ETHICS method is that it is unworkable (Avison and Fitzgerald, 1995) as the use of committees to make decisions means that unskilled workers could make decisions about very technical applications. 
Another argument against ETHICS is that it removes the rights of managers to manage, which could have dramatic impacts in the development of the system as well as cause conflict issues within the organisation. The strong focus of the ETHIC method on participation affords it many benefits as discussed earlier in the paper However this strong use of participation can also cause problems in a systems development process including:

- management/workforce distrust;

- $\quad$ working with managers tends to inhibit workforce;

- conflicts of interest between stakeholders/stress;

- $\quad$ users can't visualise rapidly developing computing possibilities;

- $\quad$ team working skills are required;

- $\quad$ consensual solutions unlikely to be radical;

- technical experts feel demoted to advisers.

The simple answer to this is that each systems development project needs to be assessed as being suitable for the use of ETHICS as in the case of any chosen methodology. One methodology may suit a particular development well whilst another would prove to be incredibly ineffective. In the "correct" situation ETHICS can provide an invigorating and dynamic experience for an entire organisation.

Mumford (2003) argues that ETHICS places emphasis on identifying new approaches to tasks and problems and new relationships within and outside the organisation and that this is the strength of ETHICS. Mumford (1996) also argues that importance of designing for the future, hence the structural approach to ensure successful design. Mumford was also interested in change and the way it is reflected in society and organisations. She accepted change as a principle that pervades modern societies and their organisations. At the same time, she believed that change is not something that must be suffered passively but that should be embraced. Change must "always be accepted by the participants" (Mumford and Ward, 1968; Stahl, 2007).

Examining the basis for Mumford's work is a refreshing change from reviewing the literature concerning many other methodologies. Where other methodologies make assumptions about the intent of the various stakeholders and concentrate on structure and process issues, Mumford is interested in values and their relationship to technology and work.

Much of Mumford's research has focussed upon the discourse between technology, organisations and staff within those organisations. These issues are as important now as they were in the late 1960's. The authors intend to carry on Enid Mumford's research into Socio-Technical approaches looking at issue in relation to Information Security and the impact that Internet based systems can have, the authors have already used a variation of ETHICS called SIM-ETHICS to assist in the implementation of security technologies within an organisation (Warren and Batten, 2002).

\section{Conclusion}

Enid Mumford passed away in 2006. Her research achievements were recognised by a number of international prizes. In 1983, she won the US Warnier prize for her 
contributions to information science research. In 1999, she won a Leo lifetime achievement award of the Association for Information Systems (The Guardian, 2006).

Enid Mumford made a major contribution to research in a number of areas, in the authors opinion one of her key research findings was Mumford and Beekman (1994):

"If a technical system is created at the expense of a social system, the results obtained will be sub-optimal."

The other major contribution is that the findings that she made at the start of her research in the 1970's are still current in the early part of the twenty first century. In 1974, she identified (Hedberg and Mumford, 1974):

Perhaps the strongest influence that changes the practice model held by the systems designers will be when the users get up and shout "we are not as you think we are".

This statement is as relevant now as it was then, and demonstrates that Enid Mumford's research will be applicable for many more decades to come.

\section{References}

1. Avison, D.E., Fitzgerald, G.: Information Systems Development: Methodologies, Techniques and Tool, 4th edn. McGraw-Hill Education, UK (2006)

2. Avison, D.E., Fitzgerald, G.: Information Systems Development: Methodologies, Techniques and Tools, 2nd edn. McGraw-Hill, UK (1995)

3. Davis, G.B., Lee, A.S., Nickles, K.R., Chatterjee, S., Hartung, R., Wu, Y.: Diagnosis of an information systems failure: A framework and interpretative process. Information and Management 23, 293-318 (1992)

4. Hedberg, B., Mumford, E.: The Design of Computer Systems. In: Proceedings of the IFIP Conference on Human Choice and Computers, Vienna, Austria (1974)

5. Legge, K., Mumford, E.: Designing Organisations for satisfaction and Efficiency. Gower Press, UK (1978), ISBN 0-566-02102-1

6. Mumford, E.: Computers, Planning and Personnel Management. Institute of Personnel Management, UK (1969)

7. Mumford, E.: Job Satisfaction: A study of Computer Specialist's. Longman Group Publishers, UK (1972), ISBN 0-582-45008-X

8. Mumford, E.: Values, Technology and Work. Martinus Nijhoff Publishers, The Netherlands (1981), ISBN 90-247-2562-3

9. Mumford, E.: Designing Participatively. Manchester Business School, UK (1983a), ISBN 0-903808-29-3

10. Mumford, E.: Designing Human Systems. Manchester Business School, Manchester (1983b), ISBN 0-903808-285

11. Mumford, E.: Designing Secretaries. Manchester Business School, Manchester (1983c), ISBN 0-903808-250

12. Mumford, E.: Using computers for Business. Manchester Business School, Manchester (1986)

13. Mumford, E.: Designing Human Systems For Health Care, The ETHICS Method, 4C Corporation, Netherlands (1993), ISBN 90-74687-01-6 
14. Mumford, E.: Effective Requirement Analysis and Systems Design. The Ethics Method, Macmillan (1995)

15. Mumford, E.: Systems Design: Ethical Tools for Ethical Change Method. Macmillan, UK (1996)

16. Mumford, E.: Redesigning Human Systems. Information Science Publishing, Idea Group Inc., USA (2003), ISBN 1-59150-118-6

17. Mumford, E., Beekman, G.: Tools for change \& Progress. CSG Publications, The Netherlands (1994), ISBN 90-75198-01-9

18. Mumford, E., Banks, O.: The Computer and the clerk. Routledge \& Kegan Paul Limited, UK (1967)

19. Mumford, E., Henshall, D.: A participative approach to computer systems design. Associated Business Press, UK (1979), ISBN 0-85227-221-9

20. Mumford, E., MacDonald, W.: XSEL'S Progress: The Continuing Journey of an Expert System. John Wiley \& Sons Ltd., UK (1989), ISBN 0-471-92322-2

21. Mumford, E., Ward, T.B.: Computers: Planning for People. Batsford Limited, UK (1968)

22. Mumford, E., Weir, M.: Computer systems in work design - the ETHICS method. Associated Business Press, UK (1979), ISBN 0-85227-230-8

23. Nurminen, N.: People of Computers: Three ways of Looking at Information Systems. Chartwell-Bratt, Sweden (1988), ISBN 0-86238-184-3

24. The Guardian. Obituary: Enid Mumford (2006), http: / /www. guardian.co.uk/news/2006/may/03/guardianobituarie s.obituaries (accessed January 10, 2010)

25. Stahl, B.C.: ETHICS, Morality and Critique: An Essay on Enid Mumford's SocioTechnical Approach. Journal of the Association of Information Systems 8(3) (2007), ISSN: 1536-9323

26. Warren, M., Batten, L.: Security Management: An Information Systems Setting. In: Batten, L.M., Seberry, J. (eds.) ACISP 2002. LNCS, vol. 2384, p. 257. Springer, Heidelberg (2002) 